REVISTA X, Curitiba, volume 14, n.4,p. 200-221, 2019

\title{
VISIBILIDADE LGBTQIA+ E EDUCAÇÃO LINGUÍSTICA: POR ENTRE OS DISCURSOS DE ÓDIO, ACEITAÇÃO E RESPEITO
}

LGBTQIA $+{ }^{1}$ visibility and language education: In between discourses of hate, acceptance and respect

\section{Daniel de Mello FERRAZ - USP ${ }^{2}$}

RESUMO: Esta pesquisa busca entrelaçar três conceitos-chave na sociedade contemporânea com a educação linguística (MONTE MÓR, 2018, FERRAZ, 2016, 2018), a saber: o neoliberalismo (BIANCHETTI, 1996), as mídias de massa e a(s) homossexualidade(s). Embora possam parecer conceitos distantes, propomos que sejam entendidos como discursos e práticas que se entrecruzam e influenciam enormemente a educação linguística. Desse modo, brevemente discorremos sobre a doxa neoliberal e suas influências e consequências na educação, tecendo algumas considerações sobre o neoliberalismo e a sexualidade (homossexualidade). Posteriormente, refletimos sobre como algumas mídias de massa colaboram com uma recente "aceitação" (e não necessariamente respeito) da homossexualidade na sociedade brasileira. Como exemplo, problematizamos a presença de personagens gays e lésbicas em duas telenovelas brasileiras. Por fim, apontamos para alguns desafios que a formação de professores de línguas deve enfrentar se deseja incluir os temas da homofobia, diferença e respeito em suas agendas, buscando responder às seguintes questões: A formação docente deve incluir esses temas em suas agendas ou deve deixá-los (como se tem feito) para outras áreas do conhecimento? O que o formador pode fazer em suas aulas no que tange às diferenças raciais, sexuais e de gêneros, principalmente quando elas emergem de suas próprias aulas? Interessa às comunidades LGBTQIA+ uma visibilidade da aceitação?

PALAVRAS-CHAVE: Neoliberalismo, Mídias de massa, Homossexualidades, Educação em LI, Formação docente.

\begin{abstract}
This research aims at connecting three key contemporary social concepts (neoliberalism, mass media and homosexuality) with language education (MONTE MÓR, 2018, FERRAZ, 2016, 2018). Even though they may seem distant concepts, we suggest that they be perceived as discourses and practices that intertwine amongst each other, and greatly influence English language education. Thus, we briefly discuss the neoliberal doxa (BIANCHETTI, 1996) and its influences on education. In this section, some considerations about neoliberalism and sexuality (homosexuality) are presented. In the second section, we discuss how mass media have greatly collaborated with a recent "acceptance" (not necessarily respect) of homosexuality in Brazilian society. As an example, we problematize the presence of gay and lesbian characters in two Brazilian soap operas. Finally, we point to some challenges that teacher education must face if it wishes to include themes such as

\footnotetext{
${ }^{1}$ LGBTQIA+ (Lesbians, Gays, Bisexuals, Transgender, Queer/Questioning, Intersex, Asexual/Ally, and more). Disponível em https://www.nytimes.com/2018/06/21/style/lgbtq-gender-language.html Acesso em 16 dez 2018.

${ }^{2}$ Pós-Doutor em Estudos Linguísticos e Literários em Inglês. Email: danielfe @usp.br
} 
homophobia, differences, and respect in their agendas. We seek to answer the following questions: Must teacher education include these themes in their agendas or must it leave them - as it has routinely been done - for other fields? What can the teacher educator do in her/his classes regarding racial, sexual and gender differences, especially when they emerge from the students? Are the LGBTQIA+ communities interested in a visibility based upon acceptance?

KEYWORDS: neoliberaslim, mass media, language education, homosexuality

\section{INTRODUÇÃO}

Os treinamentos para os professores de línguas (décadas de 90 e 2000) reforçaram que ensinar uma língua estrangeira (ou materna) significava desenvolver as quatro habilidades por meio de funções comunicativas, porém que nunca se deveria abordar temas considerados "polêmicos" ou tabus, uma vez que esses temas pertenciam a outras disciplinas. A esse respeito, Flood (2016, p. 1), afirma que os autores de materiais didáticos para ensino e aprendizagem de inglês devem veementemente evitar os PARSNIP, sigla em inglês que se refere aos temas "politics, alcohol, religion, sex, narcotics, isms (communism for example) and pork". Ainda segundo o autor,

[De acordo com] o autor Nicola Prentis "Coisas como os relacionamentos gay são absolutamente um NÃO-NÃO - muitos autores se perguntam por que não podemos, às vezes, incluir uma foto de um casal que por acaso é formado por dois homens, sem fazermos um alerde sobre isso? Outros temas que não podemos mencionar são 'cachorros' - por algumas razões; porque isso pode ofender aos coreanos, ou muçulmanos (embora gatos possam!) [....] o ELT (Ensino de Língua Inglesa) é reconhecido por ser insosso, isso porque temos que excluir muita coisa. O que nos sobrou é o contexto e um tema, por exemplo 'comer em um restaurante' - mas neste caso não poderíamos nunca ter um vinho sobre a mesa! (FLOOD, 2016. p. 1, tradução minha). ${ }^{3}$

Corroborando Flood acima, a educação linguística (TAKAKI; MONTE MÓR, 2017) busca problematizar essas visões de treinamento e do que se pode ou não ensinar e discutir em uma aula de línguas. Por exemplo, os discursos "aprender uma LE abre portas para o mundo globalizado", "O inglês é uma língua franca", "Aprende-se LE para se comunicar" são os grandes mitos/narrativas que sustentam a indústria de ELT

\footnotetext{
${ }^{3}$ According to the author Nicola Prentis "Things like gay relationships are an absolute no-no - a lot of writers feel why can't we sometimes have a photo of a couple who happen to be men, without making an issue of it? Other topics we can't mention are dogs - for a couple of reasons, because it might offend Koreans, or Muslim (cats are OK), horoscopes and gambling”. [.... ELT is renowned for being bland, because we have to take out so much. All we're left with is the environment as a topic, or eating in a restaurant - but then you could never have a wine bottle on the table (FLOOD, 2016. p.1).
} 
não somente no Brasil, mas em diversos países onde a LI é ensinada como LE ou L2. Trata-se de mitos/narrativas naturalizados/as, pois abarcam discursos generalizantes e, ainda, fomentam imaginários sociais de necessidade e mercantilização da LI.

Assim, esta reflexão se apoia nas OCEM-LE (BRASIL, 2006), para as quais o desafio de conciliar as perspectivas linguísticas e socioculturais/críticas no ensinoaprendizagem de LE/LI (ou o que muitos pesquisadores vêm chamando de educação linguística em LE/LI) é premente. Ainda, baseia-se na Linguítica Aplicada Crítica de Pennycook (2010), cujos preceitos defendem a inclusão das discussões sobre raças, gêneros, sexualidade, política e criticidade no bojo das pesquisas da LA. Alicerçados nas perspectivas de expansão do olhar e construção de sentidos (MONTE MÓR, 2008), buscamos responder a tal desafio por meio do entrelaçamento de três conceitos-chave na sociedade contemporânea com a educação linguística, a saber: o neoliberalismo, as mídias de massa e a(s) homossexualidade(s). Embora possam parecer distantes, propomos que sejam entendidos como discursos e práticas que se entrecruzam e influenciam enormemente a educação linguística em LI. Desse modo, o artigo está divido em três seções: na primeira, discorremos sobre a doxa neoliberal e suas influências e consequências na educação; posteriormente, uma reflexão sobre como algumas mídias de massa colaboram enormemente com uma recente "aceitação" (e não necessariamente respeito) da homossexualidade na sociedade brasileira é apresentada. Como exemplo, problematizamos a presença de personagens gays e lésbicas em duas telenovelas brasileiras. Por fim, alguns desafios que a formação de professores de línguas deve enfrentar se deseja incluir os temas da homofobia, diferença e respeito em suas agendas são discutidos.

Ensejamos, ainda, levantar algumas inquietações: Existe uma "aceitação" recente da homossexualidade em nosso país? Em caso afirmativo, essa "aceitação" se dá por meio dos discursos que circulam? De que forma as mídias de massa, tais como a televisão, os jornais e rádio, contribuem com o debate? Ao inserirem personagens gays e lésbicas em suas telenovelas, as emissoras contribuem com o debate sobre a diversidade ou reforçam estereótipos? Estamos falando de uma nova cultura visual, diversa e transcultural ou de uma cultura visual que obedece aos ditames neoliberais? $\mathrm{E}$ na escola? Estamos preparados para lidar criticamente com tais temas? Estas são algumas inquietações que buscamos compreender nesta pesquisa.

Trata-se de uma pesquisa qualitativa, com revisão de literatura e análise de dados baseadas nas teorias críticas e interpretativistas (RICOUER, 1976, 1978) e na 
REVISTA X, Curitiba, volume 14, n.4,p. 200-221, 2019

linguística aplicada crítica (PENNYCOOK, 2010). Os resultados deste trabalho sugerem que a força neoliberal, alavancada pelas mídias de massa, é avassaladora e imprime suas doxas (vendas, lucros, violências) promovendo uma visibilidade recente das comunidades LGBTQIA+ por meio da "aceitação", e não do respeito em relação às diversas e múltiplas identidades de gênero em nossa sociedade.

\section{O NEOLIBERALISMO E O DISCURSO DE “ACEITAÇÃO” DA HOMOSSEXUALIDADE}

Para entendermos o novo liberalismo (neoliberalismo), devemos voltar às suas raízes liberais. O liberalismo é um dos alicerces da sociedade moderna e, assim como o positivismo, iluminismo, cientificismo, empirismo, racionalismo e o colonialismo, ajudou a fundar os estados-nações e a regulamentar o mercado econômico. Em breves palavras, a doxa liberal teoriza que todos os cidadãos são livres e, como indivíduos livres, têm direito à cidadania, ou seja, direito de ir e vir e o direito de consumir tudo que necessita ou deseja.

O livre comércio entre os estados-nações também se dá via esta lógica. Acontece que, na vida cotidiana, a doxa liberal, embora bastante interessante do ponto de vista da liberdade individual, alimenta e mantém um sistema capitalista desigual na medida em que "somos todos livres, mais uns são mais livres do que os outros", uma vez que "As desigualdades sociais são equivalentes às desigualdades do mundo natural (que por outra parte garante o seu equilíbrio) e qualquer intento para modificá-las vai contra a natureza" (BIANCHETTI, 1996, p. 45). Ainda segundo o autor, "este modelo representa uma síntese do liberalismo econômico (leis do mercado) com o elitismo político" (idem, p. 45). Para citar um exemplo concreto, todos os cidadãos têm a liberdade para comprar um carro, uma casa ou um computador. Porém, todos, mesmo com o desejo, podem comprá-los? A mesma lógica se repete em relação à cidadania, ou seja, temos o direito de ir e vir, entretanto, uns têm o direito de, por exemplo, ir à pé, por quilômetros, para a escola enquanto outros têm o mesmo direito, porém de carro blindado com motorista particular.

A lógica neoliberal negligencia o direito e a liberdade à cidadania na medida em que aqueles que possuem capitais simbólico, cultural e social maiores, têm mais e melhores condições de escolha (WINDLE, 2014). Ao ingenuamente proclamar a liberdade, o neoliberalismo escamoteia coletividades econômicas e sociais, bem como as suas disparidades: "o preço desse sistema (neo)liberal tem sido pago pelo cidadão 
individual, que se sente deixado de lado, sem poder, alienado de um mercado que é dirigido pela ganância, por imensas corporações transnacionais e por um governo à mercê daquele que lhe pague mais" (SAID, 2007, p. 90).

Assim é que o neoliberalismo é a continuidade do projeto liberal em tempos contemporâneos de capitalismo acelerado. "A avassaladora ideologia neoliberal, cuja ideia-força de efeito letal é a de fazer crer que não há outra saída para a humanidade se não curvar-se à férrea lógica do mercado (lei do mais forte)" (BIANCHETTI, 1996, p. 9). O novo liberalismo fala sobre oportunidades livres e igualitárias, mas se por alguma razão o indivíduo não for capaz de se manter no topo, ele irá afundar. A esse respeito, podemos asseverar que

O que desapareceu foi a noção de que os cidadãos devem ter direitos garantidos pelo Estado, à saúde, à educação, à moradia e às liberdades democráticas. Se todos esses direitos se tornarem uma presa do mercado globalizado, o futuro será extremamente inseguro para a grande maioria das pessoas, apesar da retórica tranquilizadora (mas profundamente enganosa) de preocupação e bondade disseminada pelos gerentes da mídia e experts em relações públicas que controlam o discurso público (SAID, 2007, p. 91).

Um exemplo de como a lógica neoliberal vem contribuindo para maior visibilidade e, talvez, "aceitação" (os termos aceitação e respeito serão discutidos na última seção) da comunidade LGBTQIA+ no Brasil foi a comemoração do dia internacional contra a homofobia, no dia 17 de maio de 2013, a qual possibilitou o visionamento de diversas campanhas publicitárias na televisão e nas redes sociais:

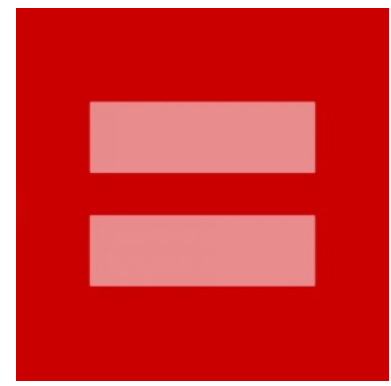

Imagem 1

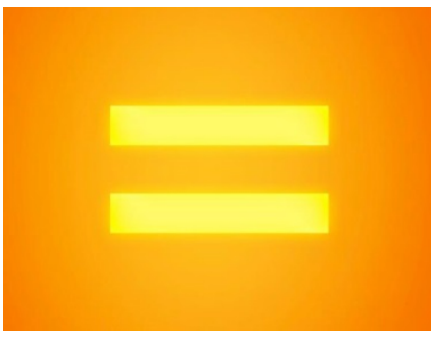

Imagem $2^{4}$

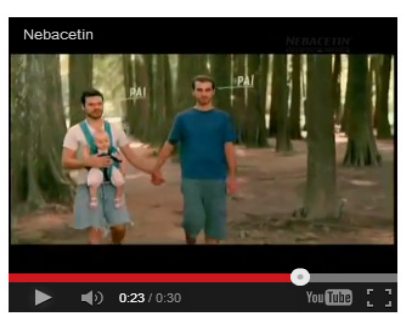

Imagem $3^{5}$

O dia em que são lembradas e comemoradas a diversidades sexuais e de gêneros tem como símbolo o sinal matemático de igual. Iniciada nos Estados Unidos pela

\footnotetext{
4 Disponível em http://juliosevero.blogspot.com.br/2013/04/itau-ponto-frio-e-outras-5-empresas.html Acesso em $10 \mathrm{dez} 2018$.

${ }^{5}$ Disponível em http://gplaneta.blogspot.com.br/2012/06/nebacetin-e-itau-na-luta-contra.html Acesso em 10 dez 2018.
} 
REVISTA X, Curitiba, volume 14, n.4,p. 200-221, 2019

Human Rights Campaign, "o símbolo matemático para igual, foi oferecido para compartilhamento nesta semana pela organização Human Rights enquanto a Suprema Corte norte-americana ouve os argumentos sobre a aprovação do casamento entre pessoas do mesmo sexo" . Como vimos acima, o banco Itaú (imagem 2) adaptou a cor laranja para o sinal de igual e, sob o slogan "Defender a igualdade \#issomudaomundo", defendeu a diversidade. A marca de remédios Nebacetin (imagem 3) lançou um vídeo cujo tema foi: "As famílias mudam, o jeito de cuidar não", sugerindo, assim, que um casal gay tem o direito de ter e educar os seus filhos.

O mesmo foi feito na rede social Facebook, em que milhares de pessoas alteraram as suas fotos de perfil para o mesmo sinal de igual. Ainda naquele ano, no Facebook, 26 milhões de pessoas coloriram seus perfis com a bandeira colorida ${ }^{7}$ símbolo da causa LGBTQIA+ - em apoio à aprovação definitiva do casamento homoafetivo nos Estados Unidos.

Sob a ótica neoliberal é possível levantar algumas hipóteses em relação a essas campanhas. Hipotetizamos que essas campanhas podem estar relacionadas a outros interesses, que não os da defesa da existência e direitos das comunidades não heteronormativas. Dessarte, é sabido que o interesse maior de uma empresa é a obtenção de lucros. Ora, já que grande parte da comunidade LGBTQIA+ tem sido pesquisada, mensurada e proclamada como "consumidores de alto potencial" por seu "bom gosto", então, por que não atingir este nicho de mercado? Segundo o Observatório Rio G $(2018)^{8}$, o Brasil é o segundo maior mercado LGBT do mundo. Ainda segundo o Observatório, o relatório revelou que "os gastos feitos entre os membros da diversidade no mundo todo já superam a marca de US\$ 218 bilhões (cerca de R \$ 813 bilhões). Deste universo, U\$ 26,8 bilhões (R\$ 100 bilhões) apenas utilizados no turismo brasileiro" (idem, p. 1).

Sobre a relação entre a homossexualidade e consumo, Altaf e Troccoli (2011) asseveram que

Portanto, de acordo com todos esses dados, podemos supor que os homossexuais - homens e mulheres - que se afirmam como tal representam uma boa fatia da população. Ademais, pelo menos uma

\footnotetext{
6 Disponível em http://www.jornaltudobh.com.br/tudo-mais/sinal-de-igual-vira-simbolo-de-defesa-docasamento-gay/ Acesso em $10 \mathrm{dez} 2018$.

${ }^{7}$ Disponível em http://mixbrasil.xpg.uol.com.br/pride/26-milhoes-colorem-seus-perfis-no-facebook-emapoio-ao-casamento-.html Acesso em $10 \mathrm{dez} 2018$.

8 Disponível em_h https://observatoriog.bol.uol.com.br/noticias/2018/11/brasil-e-o-segundo-maiormercado-lgbt-do-mundo Acesso em 16 dez 2018.
} 
REVISTA X, Curitiba, volume 14, n.4,p. 200-221, 2019

parte deles seria uma massa de alto poder aquisitivo, com escolaridade acima da média e consumidores requintados, que desejam produtos e serviços de qualidade, com valor elevado e duradouros [...] Em outras palavras, os homossexuais representariam um importante nicho consumidor (ALTAF; TROCCOLI, 2011, p. 10).

Por se tratar de uma pesquisa quantitativa e restrita a um público específico, não é possível transferir os dados da pesquisa de Altaf e Troccoli para toda a comunidade LGBTQIA+ do país. Outrossim, para este estudo vamos nos ater aos discursos da mídia em torno dessas comunidades, embora seja certeiro reconhecer a diversidade de classes sociais, econômicas e educacionais existente em cada Letra da sigla supracitada. Entretanto, chamamos a atenção para esse discurso generalizante que vem sendo reforçado por aqueles que estudam os padrões de consumo no Brasil, qual seja, "ser gay significa bom gosto e alto consumo". Ainda a esse respeito, as mesmas autoras complementam que não é para menos que o pink money (expressão utilizada para denominar o consumo específico de gays, lésbicas e transgêneros) vem sendo cada vez mais valorizado em todos os tipos de mercado. "Afinal, quem não quer servir a um nicho - e lucrar com ele - que, de acordo com a ABRAT, gasta anualmente, no Brasil, 6,5 billhões de dólares apenas com lazer e entretenimento?" (ALTAF; TROCCOLI, 2011, p. 104). Com isso, são dois desdobramentos possíveis: 1. As empresas se tornam amigáveis (GLBTQIA+/gay friendly) da causa das comunidades LGBTQIA+ e, para esta comunidade minoritária, adquirem respeito e credibilidade; 2. Aumentam seus lucros neste nicho específico, considerados "exigentes" e possuidores de capital econômico.

Vale ressaltar, ainda, que as campanhas supracitadas (Itaú e Nebacetim), bem como a maioria dos discursos que circulam, focalizam somente homens gays bem sucedidos, quais sejam, todos dentro da matriz heterossexual de beleza. Exclui-se, assim, uma gama de identidades de gênero/sexuais que não se encaixam nesses padrões, como por exemplo as ensejadas no espectro das identidades de gênero LGBTQIA+ (Lésbicas, Gays, Bi, Trans, Queer/Questionando, Intersexo, Assexuais/Arromântiques/Agênero, Pan/Poli, e mais ${ }^{9}$ ). Assim é que gays efeminados, "caricatos", "poc/pocs", drag queens, lésbicas, "sapatões", transgêneros, entre tantos outros, são geralmente excluídos do modelo neoliberal, heterossexista e heteronormativo do mercado. Por exemplo, em relação às personagens gays efeminados e caricatos da televisão, McGovern (2011) afirma que "o público aprendeu a ter medo

${ }^{9}$ Disponível em https://orientando.org/o-que-significa-lgbtqiap/ Acesso em 16 dez 2018. 
REVISTA X, Curitiba, volume 14, n.4,p. 200-221, 2019

deste comportamento ao mesmo tempo em que se diverte com exemplos de ridicularização de tais personagens estereotipados" (McGOVERN, 2011, p. 7, tradução minha). Ainda segundo a autora, ao criar personagens que levam ao riso, o público é capaz de afastar a ideia de que as personagens LGBT são "seres humanos reais", ou seja, estão longe de pertenceram à sua família ou círculo de amizades. Em contraponto, vale ressaltar que, mesmo homo-heteronormatizadoras, tais campanhas não teriam sido veiculadas em décadas passadas e, portanto, podem ser consideradas avanços por muitos que defendem os movimentos LGBTQIA+.

\section{CULTURA VISUAL E AS MÍDIAS DE MASSA}

A cultura visual (CV) e as mídias de massa são grandes veículos do projeto neoliberal na medida em que podem circular globalmente via internet, rádio, jornal, revista, televisão e na medida em que são, no caso das mídias de massa deste país, controladas, em sua maioria, por famílias tradicionais e políticos, os quais buscam, além do lucro, manter poderes, privilégios e visões ideológicas. Nos entendimentos de Mertel e Lazerfeld (2000), as mídias de massa "conferem prestígio e acrescentam a autoridade de indivíduos e grupos, legitimando seu status". É justamente nesse sentido que entendemos a maior aceitação da homossexualidade, qual seja, como se descobriu que este grupo de indivíduos possui capacidade e poder de consumo, talvez as mídias de massa venham lhe conferindo maior prestígio e atenção.

Dialogando com Mizan (2014), a sociedade moderna está invadida pelo poder da imagem, uma vez que produz e consome imagens como nunca antes. Ainda segundo a autora, estamos vivendo em um período que é mais visual do que linguístico, pois as novas mídias promovem a representação e a expressão visual como formas de comunicação. Além disso, as imagens trazem informações, proporcionam prazer e desprazer, influenciam estilos, determinam consumos e medeiam as relações de poder (ROGOFF, 2000). Há de se compreender, ainda, os dois níveis emergentes no campo da cultura visual: o primeiro focaliza o mundo visual como produtor de significados e de mantenedor dos valores estéticos, estereótipos de gênero e relações de poder cultural. Em outro nível, considera-se a abertura do campo da visualidade como uma arena na qual os significados culturais são constituídos, ancorados numa gama de interpretações das dinâmicas aurais, espaciais e psíquicas do espectador (ROGOFF, 2000).

Nesse sentido, as mídias de massa interessam, pois, além de representarem e, ao mesmo tempo, alimentarem o neoliberalismo (é na verdade um de seus pilares), 
interpelam a todos via comunicações locais, regionais, nacionais e, hoje em dia, globais. Para Merton e Lazarsfeld (2000), “o poder econômico parece ter se reduzido à exploração direta, voltando-se para um tipo mais sutil de exploração psicológica alcançada em grande parte pela propaganda disseminada pelos mass media" (MERTON; LAZARFLED, 2000, p. 110). Complementam os autores que

A ubiquidade dos mass media nos leva à crença, quase mágica, em seu enorme poder [...] diversos tipos de controle social que poderosos grupos de poder, entre os quais o mundo do negócio organizado ocupa a posição de maior destaque, vêm adotando técnicas para manipular o público de massa pela propaganda, ao invés de empregar meios mais diretos de controle" (ibid.).

No caso específico da televisão, percebemos que seu formato básico é determinado pelas relações de produção capitalista, o que significa dizer que a televisão é dominada pelas leis do mercado e pela necessidade de vender programas e produtos. Sem o consumo de massa não haveria televisão comercial e sem a habilidade da televisão em influenciar o consumo não haveria mercado para produtos de massa. Embora muitos programas evidenciem preocupações educativas, culturais e de entretenimento, vale ressaltar o seu caráter neoliberal: todos os canais de televisão são grandes empresas de comunicação de massa.

É sabido que a televisão brasileira é um dos grandes meios de comunicação do país. As novelas das TVs Record, SBT e Globo continuam sendo grandes representantes da cultura brasileira e os grandes exemplos de comunicação e entretenimento que circulam entre as massas. É preciso, entretanto, investigar se, no caso do tema da homossexualidade, quais são os objetivos e intensões dessa inserção e visibilidade. Vimos argumentando que as mesmas conexões realizadas anteriormente sobre o neoliberalismo e a propaganda podem ser feitas em relação às mídias de massa (televisão), ou seja, a presença recente da homossexualidade em recentes telenovelas da Rede Globo pode ser interpretada como uma iniciativa que visa as altas porcentagens de audiência. Embora alguns diretores mereçam reconhecimento por intentarem realizar denúncias das diferenças sociais latentes no Brasil, é sabido que as telenovelas impõem as perspectivas desejadas pelos seus dirigentes. Nos entendimentos de Scorsolini-Comin e Santos (2012),

Para além de seu valor como obra artística ligada à dramaturgia, tal como o teatro, o cinema e outras manifestações, a telenovela constitui uma ferramenta de criação e de transmissão de crenças e costumes, de 
normas, de modos de ser e de viver, de um ethos, portanto. Moldada pela visão de mundo da classe média, a telenovela é responsável por trazer novidades às casas dos telespectadores que não possuem acesso a outras formas de comunicação e entretenimento, além de ser um retrato - nem sempre fiel - de nossa sociedade, fortemente influenciada pela cultura de massa (SCORSOLINI-COMIN; SANTOS, 2012, p. 54).

Assim é que as telenovelas brasileiras representam uma visão de realidade ao mesmo tempo em que colaboram enormemente com tal construção da realidade. Em relação à homossexualidade presente nas recentes produções da Rede Globo, Villalba (2015) afirma que "É claro que a decisão anterior de levar ao ar uma novela centralizada num homossexual já mostrava que a mentalidade mudou". Será que a mentalidade mudou ou eleva a audiência trazer personagens gays em sua maioria caricatos, engraçados e efeminados? Segundo McGovern (2011), independentemente da intenção, as representações dos homossexuais nas comunicações de massa são capazes de influenciar praticamente todas as percepções que temos sobre o tema. Além disso, a evolução dos estereótipos homossexuais depende da autoridade das mídias de massa.

Portanto, ao mesmo tempo em que podem ser pensadas como artefatos culturais nacionais e, segundo muitos, representações do que acontece na "vida real" (por exemplo, poder-se-ia afirmar que as recentes telenovelas têm incluído as homossexualidades devido aos debates sobre a homofobia na política nacional), o desejo dessa representação está intrinsicamente relacionado aos índices de audiência, ao mercado de consumidores (neste caso as comunidades LGBTQIA+) e ao lucro. Assim é que a maioria das personagens gays (homens) é caricata, provoca o riso e o distanciamento. No mesmo sentido, as personagens lésbicas são geralmente espelhos dos moldes heteronormativos (duas mulheres lindas e femininas e nunca duas “caminhoneiras"). Portanto, aceita-se o diferente, numa relação em que o sujeito aceitante / heternormativo é superior, ao passo que o aceitado continua sendo o desvio da norma, qual seja, o abjeto/estranho que provoca o riso; o homossexual será sempre aquele que depende da outorga do "normal"/superior.

\section{DISCURSOS QUE CIRCULAM}

Nesta seção, analisamos alguns discursos divulgados na mídia sobre duas telenovelas de grande sucesso e circulação, em que personagens gays e lésbias faziam parte das narrativas. Discutimos ambas as visões advindas de revistas de cotidianos (por 
meio de suas reportagens), bem como os discursos dos leitores de tais revistas (por meio da análise dos comentários online postados abaixo das reportagens).

A telenovela Amor à vida (2014) foi uma das primeiras que apresentou um casal gay entre os personagens principais. Assim, foi por meio da personagem Félix, "a bicha má”, que grande parte dos brasileiros pôde construir alguns significados sobre um homem gay. Segundo Villalba (2015), "eis que um casal homossexual conseguiu fazer o público reviver a expectativa do amor, trajetória que teve torcida desde a primeira cena até o final feliz e inédito na história das novelas que vimos na noite desta sexta". Segundo a Revista VEJA ${ }^{10}$, "o Beijo gay faz de Amor à Vida um marco da TV" (VILLALBA, 2015). A respeito da última cena da novela, a autora afirma que

Félix e Niko foram grandes personagens, duas faces de uma moeda que desejou espelhar na novela o tema da aceitação. Um, solar e bemsucedido, feliz com sua homossexualidade. O outro, soturno e amargo, atormentado pelo pai homofóbico. Foi um grande drama gay, cheio de bordões sagazes e divertidos (idem, p.1).

De acordo com Villalba, o discurso da aceitação é o desejo da novela ao trazer as personagens para o foco. Aceitar aqui significa aceitar a homossexualidade, ou seja, da posição superior da matriz heterossexual/ hetenormativa, aceita-se aquele que é inferior, divergente da matriz, o homossexual. Porém, não se problematiza as dicotomias e os estereótipos reforçados despercebidamente no discurso acima, pois é justamente a visão estereotipada que se busca construir em relação aos homossexuais masculinos no Brasil: são efeminados, engraçados, divertidos e nos fazem rir. Reiteramos que não há problema algum com tais clichés porque estes certamente existem em nossa sociedade. Entretanto, a generalização e a construção da homossexualidade masculina (gays são bichinhas, mulherzinhas, divertidas, etc.), da homossexualidade feminina (lésbicas são mulheres-machos, sapatões, rudes, maleducadas, etc.) e da transexualidade (transgêneros somente fazem "programas", são cabeleireiras, etc.) reforçam as dicotomias produzidas no seio da heteronormatividade, ou seja, "eles, heterossexuais, são normais/superiores, nós, os homossexuais, somos diferentes/inferiores/engraçados". Prosseguindo, Villalba (ibid.) afirma que "Em clima de harmonia familiar, Félix (Mateus Solano) e Niko (Thiago Fragoso) deram um beijo de amor, em boa medida de empolgação para o relacionamento dos personagens". E

10 http://veja.abril.com.br/blog/quanto-drama/folhetinescas/cercado-de-torcida-beijo-gay-faz-de-amor-avida-um-marco-da-tv/ Acesso em 20/06/2015. 
Villalba (idem) complementa: "Foi apaixonado, mas não singelo; verdadeiro, mas com cuidado para não chocar".

O que significa "com cuidado para não chocar"? Significa que um beijo entre dois homens ainda choca a sociedade. Na esteira das discussões que vimos tecendo, o tão esperado beijo gay da telenovela global não foi nada estarrecedor (muito menos singelo!): foi o que os jovens hoje em dia chamam de selinho (um beijo rápido, de tocar lábios). Ou seja, mesmo que o beijo tenha acontecido, aconteceu em forma de selinho (e não como os tantos outros beijos longos, amorosos e acalorados das personagens heterossexuais da mesma novela). Depreendemos de tal "selinho" a mesma dicotomização: "nós, os heterossexuais, permitimos que vocês, os homossexuais deem um único beijo na novela, mas que esse beijo seja inferior aos tantos outros beijos que nós, heterossexuais podemos dar, pois somos a norma: nós podemos, vocês não".

Muitos dos comentários postados sobre essa reportagem da Veja reforçam o argumento de que ainda há muito se a debater se desejamos conectar os temas respeito, aceitação, educação e sociedade:

\section{Frederico $^{11}$}

\section{$1 / 2 / 2014$ às $14: 57$}

Ainda bem que não perco meu precioso tempo com esse lixo de emissora. Certamente se tivesse visto o tal beijo gay, teria corrido para o banheiro para vomitar. Homem como homem me dá náuseas, nojo. Agora peçam para os dois transarem e arrumarem um filho. Ops, por meio natural isso não será possível porque só pode acontecer entre um homem e uma mulher. Sociedade falida, sem rumo (grifos nossos).

\section{Nunes}

1/2/2014 às 15:02

Cá pra nós trocar uma mulher pro outro homem é insanidade mental em último grau. Incompreensível.

\section{Maurício}

1/2/2014 às 15:03

Asqueroso e nojento, vou vomitar!

As visões acima rechaçam a presença da homossexualidade nessa telenovela e reforçam os padrões heteronormativistas, os quais, em tempos extremamente neoconservadores em nosso país, pretendem ditar o que entende por escola, religião e família. Vale ressaltar, assustadoramente, que para Frederico, Nunes e Mauricio acima, não se trata de aceitar o diferente, mas de que a simples presença da homossexualidade

\footnotetext{
${ }^{11}$ Todos os comentários foram mantidos na maneira que foram escritos pelos internautas.
} 
masculina lhes causa "asco, nojo, vontade de vomitar"; trata-se, para eles, de “insanidade mental”. Esses discursos defendem a patologização da homossexualidade, a qual foi historicamente colocada como doença por muitas décadas na sociedade ocidental contemporânea. Embora tenha sido retirada do quadro de doenças por associações médicas internacionais e nacionais, percebe-se que esse discurso é ainda bastante presente. No primeiro comentário, Frederico coloca, ainda, a visão, mormente religiosa, de que o natural/normal é o homem e a mulher heterossexuais, haja vista que somente ambos podem procriar. Em contrapartida, na mesma lista de postagens, relatase os seguintes discursos:

\section{Filósofo Bêbado}

1/2/2014 às 15:43

Entendo por que Marilena Chauí chama a classe média conservadora de burra. Ela tem razão, mas não cem por cento. O povo acha que todos acreditam em Deus logo coisas diferentes, que vão além dessa bipolaridade esquizofrênica de concepção do mundo (bem x mal, Deus x Diabo, macho x fêmea) imposta como verdade absoluta e imutável, são tidas como loucura, apostasia e até crime contra "a moral e os bons costumes". O mundo evolui, quer queiramos, quer não. A barbárie bate a porta e a preocupação deste povinho é se duas pessoas do mesmo sexo podem ser representados numa novela em horário nobre. Pobre Brasil, não sei como aqui têm prédios e aviões dada mentalidade deste povo.

MYRNA SOUZA

1/2/2014 às $17: 31$

AMEI O BEIJO GAY VAMOS ACABAR C A HOMOFOBIA Q NINGUEM MERECE

\section{Sergio}

$1 / 2 / 2014$ às $20: 16$

Não é um beijo gay que destrói a tradicional família brasileira. É um pai chegando em casa bêbado e batendo na mulher. É o padre/pastor pedófilo. É o estuprador filhinho de papai. É esse criação machista que cria expectativas falsas nos meninos e nas meninas. É essa falta de caráter dos políticos, é essa hipocrisia de xingar o presidente de ladrão mas querer tirar vantagem dos outros em tudo. É um pai/uma mãe dando péssimos exemplos em casa: traição, desrespeito, violência física e psicológica...

Em direção oposta, os três discursos acima defendem a presença dos casais gays na novela. Praticamente revoltado, o filósofo bêbado fundamenta-se na filósofa Marilena Chauí para registrar seu desânimo com a sociedade brasileira a qual, segundo ele, deveria problematizar as dicotomias impostas pela religião, ou seja, deveríamos questionar a bipolaridade esquizofrênica de concepção do mundo (bem versus mal, Deus versus Diabo, macho versus fêmea) imposta como verdade absoluta. Outro 
protesto foi feito por Mirna: "Vamos acabar com a homofobia que ninguém merece". E Sergio complementa elencando diversos problemas que são muitas vezes enfrentados pelas famílias: pedofilia, sexismo, machismo, educação sexual e religiosa e violência. Uma possível interpretação dos discursos revoltosos acima aponta para a percepção de que os membros das comunidades LGBTQIA+ já não suportam mais as inferiorizações e as violências simbólicas e físicas sofridas.

Como último exemplo, problematizamos os discursos que reverberaram da telenovela da Globo, Babilônia, em que Fernanda Montenegro e Nathalia Timberg foram escaladas para formar casal lésbico em novela. Segundo o jornal O Estadão ${ }^{12}$, "Personagens gays têm sido cada vez mais frequentes nas novelas da Globo". Em relação à Paraíso Tropical, segundo o jornal Correio Brasiliense, "Logo no primeiro capítulo da novela Babilônia, exibido na noite desta segunda-feira (16/3), Fernanda Montenegro e Nathália Timberg se beijaram. As duas vivem um casal de lésbicas na trama. Antes do início da atração, Montenegro havia afirmado que as duas teriam cenas de intimidade. 'Os conservadores vão ter que nos aturar', disse”. Após esse capítulo, uma enxurrada de comentários foi postada:

Jess: Meu pai mudou de canal só por causa da cena do beijo gay 9:48 PM - 16 Mar 2015

Davi S: arrasou no romance, babilônia.

Igor Caetano: Pq nego da parabéns pra um novela que tem beijo gay? 9:47 PM - 16 Mar 2015

Nison Xavier: Vamos fazer panelaço em homenagem ao beijo? \#Babilônia 9:29 PM - 16 Mar 2015

Jean Willys: Beijo gay no primeiro capítulo. Um beijo entre duas mulheres mais velhas, interpretadas por duas grandes atrizes. "Babilônia" começa bem

9:31 PM - 16 Mar 2015

Astride Fontenelli: Amor!!!!! Natalia E Fernandona!!! Duas grandes damas da arte de representar!! \#orgulho \#respeito!!

IaIa: BabiloniaEstreia beijo gay já no primeiro capitulo? Que dia horrível para a familia tradicional brasileira rs 10:35 PM - 16 Mar 2015 - Nova Prata, Rio Grande do Sul, Brasil ild Ã@sio - 17de Março às 11:46

Decididamente a rede Globo de Televisão resolveu conspirar contra a família brasileira tradicional (pai, mãe e filhos) que gostam de assistir telenovelas. Como explicarei aos meus netos que beijo de línguas entre duas idosas é correto e normal! Sinceramente, estamos nos fins dos tempos!

12 http://cultura.estadao.com.br/blogs/gabriel-perline/globo-escala-fernanda-montenegro-e-nathaliatimberg-para-formar-casal-lesbico-em-novela/ Acesso em 20/06/2015 
Assim como a primeira telenovela, a segunda, agora trazendo a homossexualidade feminina, provocou reações, mormente binárias de apoio ou abominação, do sim e do não, do normal e do anormal. São discursos que nos representam e disputam, cada qual do seu lado, como se puxando uma corda para que o outro lado sucumba. Tais discursos dicotômicos demonstram o quão pouco dialogamos no que diz respeito às nossas sexualidades, às nossas identidades de gênero e, principalmente, às sexualidades e identidades de gêneros do Outro. A situação se agrava quando desejamos eliminar o Outro que não concorda com a nossa existência. Embora defendamos que: 1. Devemos lutar contra a homofobia presente nos discursos, políticas nacionais e discriminações (cada vez mais "justificadas”) de muitos brasileiros; 2. Devemos e podemos (principalmente como educadores) melhor compreender as homossexualidades, posicionarmo-nos em um lado dos polos seria cair na mesma cilada dicotômica aferida e mantida pelo positivismo, iluminismo e o neoliberalismo. Nesse assentamento em um dos lados, o diálogo perde força, esvai-se. Talvez seja o complexo diálogo freireano do "escutar-se no e com o mundo" o que mais nos falta nesse momento.

\section{(HOMOS)SEXUALIDADE(S): PERSPECTIVAS EDUCACIONAIS}

A escola não pode tudo, mas pode mais. Pode acolher as diferenças. É possível fazer uma pedagogia que não tenha medo da estranheza, do diferente, do outro. A aprendizagem é destoante e heterogênea. Aprendemos coisas diferentes daquelas que nos ensinam, em tempos distintos, [...] mas a aprendizagem ocorre, sempre. Precisamos de uma pedagogia que seja uma nova forma de se relacionar com o conhecimento, com os alunos, com seus pais, com a comunidade, com os fracassos (com o fim deles), e que produza outros tipos humanos, menos dóceis e disciplinados.

Abramowicks, Para além do fracasso escolar.

Corroborando Abramowics acima, cremos que a escola pode muito mais. Talvez necessitemos cada vez menos de seres dóceis, disciplinados e reprodutores de conhecimentos e cada vez mais de pedagogias da estranheza, do diferente e do diverso. No que diz respeito às diferenças de gênero, nossa sociedade nega a possibilidade de 
REVISTA X, Curitiba, volume 14, n.4,p. 200-221, 2019

coexistências ou se silencia frente ao preconceito e à discriminação. Como ressaltado por Mello et al (2012, p. 412), a humanidade de pessoas transexuais, lésbicas e gays é sistematicamente questionada e negada, a partir de crenças heteronormativas, naturalizantes e religiosas, incompatíveis com os princípios de respeito à dignidade, autonomia e liberdade.

Especificamente em relação à $E L T$ ou $E F L$, defendemos e praticamos, durante muito tempo, uma visão deveras linguística do processo de ensino e aprendizagem de uma LE e deixamos para fora da sala de aula, ou para as outras disciplinas, questões como a sexualidade, política e a filosofia, e assim por diante. Entretanto, os jovens estudantes parecem demandar de nós, educadores de línguas estrangeiras, práticas pedagógicas que focalizem as visões da língua como prática social, como algo em movimento e em transformação. Em um dos documentos oficiais (OCEM), Menezes de Souza e Monte Mór (BRASIL, 2006) sugerem que repensemos o ensino/aprendizagem de uma LE no país, afirmando que:

As propostas epistemológicas (de produção de conhecimento) que se delineiam de maneira mais compatível com as necessidades da sociedade atual apontam para um trabalho educacional em que as disciplinas do currículo escolar se tornam meios. Com essas disciplinas, busca-se a formação de indivíduos, o que inclui o desenvolvimento de consciência social, criatividade, mente aberta para conhecimentos novos, enfim, uma reforma na maneira de pensar e ver o mundo (BRASIL, 2006, p. 90).

Portanto, diversos movimentos educacionais contemporâneos (letramentos, letramentos críticos, novos letramentos, multiletramentos, educação crítica em LE) têm apontado para o que as Orientações Curriculares sugerem: uma reforma na maneira de pensar e ver o mundo em tempos de significativas transformações. Há algum tempo, temos defendido uma mudança semântica em relação à nomeação de nossa área de atuação, com objetivo de expandi-la. À luz de Giroux (1997), Monte Mór (2008), Hawkins e Norton (2009), sugerimos o termo educação linguística (ou educação de línguas estrangeiras/ educação de/em LI) ao invés de ensino/aprendizagem de línguas estrangeiras, uma vez que a inclusão o conceito de educação nos acrônimos citados ressalta o caráter filosófico-educacional-linguístico-crítico das novas práticas e teorizações em relação às línguas estrangeiras. Nesta proposta, o desafio é o de ensinar por meio da língua, ou seja, o de ensinar os aspectos linguísticos associados aos aspectos socioculturais, vendo que ambos são, na verdade, indissociáveis. Significa enxergar a língua e linguagem como essenciais nas comunicações, nas relações de poder 
e nas análises dos discursos, percebendo que é também por meio da língua/linguagem que praticamos violência simbólica (por exemplo, contra a diversidade sexual e de gêneros) e é por meio delas que declaramos guerra ou matamos (por exemplo, os inúmeros assassinatos baseados nos discursos de racismo nos Estados Unidos e no Brasil ou os eventos violentos e xenofóbicos, como o de Charles Hebdo na Europa, motivados, muitas vezes, por uma intepretação unívoca do Outro).

Em relação à educação e o neoliberalismo, Clarke e Morgan (2011) enfatizam que

Na esteira da globalização e da expansão das redes de mídias globais, os valores neoliberais, incluindo a "escolha", "liberdade", "padrão", "responsabilidade", e a crença nas forças todo-poderosas do "livre comércio" e do "mercado", tornaram-se hegemônicas nas sociedades em todo o mundo. Na educação, isso tem gerado consequências profundas nas concepções de ensino, aprendizagem, pesquisa e conhecimento e, $[. .$.$] linguagem. Na verdade, o pensamento neoliberal$ é sustentado pelo que poderíamos chamar de uma noção "empirista / idealista" da linguagem, na qual a linguagem tem uma relação direta e completa com a "experiência", a qual está diretamente comunicada e entendida, sem problematizações pelo indivíduo pré-linguístico (CLARKE; MORGAN, 2011, p. 68, tradução minha).

Assim é que o neoliberalismo, como força poderosa e provedora das grandes metáforas (ou grandes narrativas) da sociedade (pós) moderna, vem imprimindo suas marcas em muitas áreas do conhecimento, tal como a educação em línguas estrangeiras. É na esteira dos discursos de globalização que muitos estudantes constroem "um imaginário social fundamental para as relações capitalistas neoliberais”, uma vez que, ao imaginar a língua inglesa como global e essencial, acreditam em um discurso coletivo de necessidade/obrigatoriedade que os leva a estudarem a língua. Assim é que neoliberalismo e educação em LE caminham de mãos dadas. E como afirmam Clarke e Morgan acima, elas buscam manter noções empiristas, idealistas e estruturalistas da linguagem e, por conseguinte, da educação. Nesse contexto, sobra muito pouco espaço para se discutir (por meio da língua estrangeira) os assuntos caros e presentes nas vidas de muitos dos estudantes: raças, gêneros, sexualidades, homossexualidades, políticas públicas e linguísticas, mídias de massa, ideologias. Por fim, apoiados na perspectiva de educação crítica de línguas (a qual buscaria problematizar estes e tantos outros temas, ensinando por meio da língua e não somente a língua), sugerimos que, no que tange às aulas de línguas estrangeiras, a escola pode muito mais. 


\section{CONSIDERAÇÕES FINAIS}

Uma questão: acho lamentável, apesar da posição, digamos assim, até progressista, que as pessoas usem as palavras "tolerância", "acolhimento" e "aceitação". O que significa isso? Eu me sinto bem por ser, digamos assim, um pecador? $\mathrm{O}$ que significa tolerância? Esse é um conceito totalmente autoritário: "eu é que vou tolerar vocês, pois sou melhor do que vocês; então vocês serão acolhidos". Isso é um absurdo. Eu vou ser acolhido por quem? Pelo papa? É o papa que vai dizer se eu sou normal ou não? É um pastor? É um bispo? Isso é ridículo. Quem "aceita" quem?

Membro do NUANCES (Grupo pela livre expressão sexual), Religião e sexualidade: convicções e responsabilidade.

Em tempos de extremo neoconservadorismo, Escola sem Partido, reformas educacionais top-down, BNCC, entre tantos outros ataques à educação nacional e à formação docente, não desejamos encerrar o diálogo aqui, não podemos! Conectar temas aparentemente tão distantes nos é caro. Embora percebamos que as homossexualidades são compreendidas por muitos em tempos contemporâneos, afirmamos que esta compreensão vem como aceitação e isso talvez não interesse aos milhares de gays, lésbicas, transgêneros e tantas outras identidades de gênero que lutam por direitos garantidos a todos em nossa constituição e na Declaração dos Direitos Humanos.

O neoliberalismo continua promovendo suas falsas formas de "liberdade" econômica. Corroborando Said, devemos pensar que "a questão agora é quanto tempo mais o neoliberalismo irá durar [...] quanto mais sofrimento social poderemos tolerar antes que a própria necessidade de mudança cause a mudança?” (SAID, 2007, 91).

Igualmente, as mídias de massa vêm constantemente apresentando em seus comerciais, suas telenovelas, programas jornalísticos ou de entretenimento, casais gays e lésbicas, mormente gays caricatos e drag queens divertidas, contribuindo para a produção de diversos discursos em relação às homossexualidades. O intuito, no entanto, pode ser o lucro advindo dessa exposição/ridicularização. Nesse sentido, o que significa 
"aceitar" ou respeitar quando falamos de sexualidades? Vemos que tal "aceitação" se dá nos discursos, pois, o que acontece na prática, no mundo real das comunidades LGBTQIA+, é bastante diferente: o desrespeito se torna, muitas vezes, violência.

O termo aceitar, segundo o dicionário Houaiss" ${ }^{13}$, significa: "Receber de boa vontade aquilo que é oferecido: aceitar a doação; Admitir a contragosto ou aderindo: aceitamos a situação de fato; Suportar: aceitar o castigo". Defendemos aqui que o sentido de aceitar que frequentemente se coloca em relação às homossexualidades é o de admitir a contragosto ou o de suportar, no sentido de "eu te aceito, eu te suporto, pois sou superior a você (sou normal, heterossexual)".

Alguns significados para respeitar, no mesmo dicionário são: "Demonstrar ou possuir respeito por outras coisas e/ou pessoas; considerar importante: os alunos respeitam o professor; Levar em consideração: respeitava as opiniões dos colegas. Não prejudicar; poupar". Nesse sentido, respeito seria, mesmo numa escala hierarquizante, mais desejável e esperado pelas comunidades LGBTQIA+. Ao mesmo tempo, tais comunidades, ao reclamar respeito, devem respeitar o Outro.

Pensando de maneira autocrítica, estamos conscientes de que respeito, dependendo da perspectiva, é similarmente um termo neoliberal e positivista (por exemplo, respeito na perspectiva multicultural muitas vezes se finca na ingênua ideia de "vamos viver em harmonia, vamos respeitar todos os povos e nações", buscando, assim apagar as diferenças). O sentido de respeito que defendemos aqui vem das releituras de Bhabha realizadas por Jordão (2010). Para esses autores, trata-se da consciência da diferença como espaço híbrido, de múltiplos sentidos, ou seja, "os espaços e os sujeitos, sendo híbridos e resultantes do deslocamento de sentidos, podem resistir aos discursos totalizadores e criar possibilidades de articulação de novos sentidos" (JORDÃO, 2010, p. 432). Nesses novos sentidos, há a difícil tarefa de visitar/respeitar o outro, quais sejam, as tarefas da transculturalidade e do entendimento de ambas as partes, de um entendimento em que se desconstruam as dicotomias nós versus eles, heterossexuais versus homossexuais, e se construam relações outras. Esse talvez seja o grande desafio, isto é, a produção e o espalhamento de visibilidades e (re)existências das comunidades LGBTQIA+ podem promover o diálogo, a escuta e o respeito.

E na escola? Estamos preparados para lidar criticamente com tais temas? O que tudo isso tem a ver com ensinar uma língua estrangeira? Certamente cabe ao educador,

${ }^{13}$ http://www.dicio.com.br/aceitar/ Acesso em 20/06/2015. 
REVISTA X, Curitiba, volume 14, n.4,p. 200-221, 2019

principalmente o de LE/LI, orquestrar tais temas, estejam eles presentes e escancarados em suas aulas ou não, por meio da língua. No momento em que encerramos esta pesquisa, diversas discussões e projetos de lei estão sendo debatidos no Congresso Nacional, todas a favor de um único modelo nuclear de família: uma família é composta exclusivamente por um homem e uma mulher, heterossexuais. Pensamos que não é mais possível nos ausentar desse debate, seja em nossas pesquisas, seja nas formações dos futuros educadores. Muitos deles certamente nos indagariam: "Mas como inserir tais debates? É nosso papel?". Responderemos: “Ensinar uma língua estrangeira somente terá um papel relevante em nosso país no momento em que nos posicionarmos e dialogarmos no e com o mundo".

\section{REFERÊNCIAS}

ABRAMOWICZ, A. M. (org). Para além do fracasso escolar. Campinas, SP: Papirus, 1997.

ALTAF, J. G.; TROCCOLI, I. R. Esta roupa é a minha cara: Gays, luxo e consumo. Rio de Janeiro: Garamond, 2011.

BIANCHETTI, R. G. Modelo neoliberal e políticas educacionais. Coleção Questões da Nossa Época. São Paulo: Ed. Cortez, 1996.

BRASIL. OCEM/LE. Orientações Curriculares do Ensino Médio: Línguas Estrangeiras, Linguagens, Códigos e Tecnologias. Brasília: MEC-SEB, 2006.

CLARKE, M.; MORGAN, B. Education and social justice in neoliberal times: Historical and pedagogical perspectives from two postcolonial contexts. In: M. HAWKINS, M. (Ed.), Social justice language teacher education, Multilingual Matters, p. 63-85, 2011.

FERRAZ, D. M. Should gender and sexuality studies be included in language education? Revista Trama, vol. 12, núm. 27, p. 178-201, 2016.

FERRAZ, D. M. Educação linguística e transdisciplinaridade. In: PESSOA, R. R.; SILVESTRE, V.; MONTE MÓR, W. (Orgs.). Perspectivas críticas de educação linguística no Brasil: trajetórias e práticas de professoras/es universitárias/os de inglês. São Paulo: Pá da Palavra, p. 103-117.

FLOOD, A. Pigs won't fly in textbooks. Disponível em: https://www. theguardian.com/books/2015/jan/14/pigs-textbooks-oup-authors-pork-guidelines.

Acesso em 1 dez. 2018.

FOUCAULT, M. Microfísica do poder. São Paulo: Graal, 18a ed., 2003.

GIROUX, H. Os professores como intelectuais: Rumo a uma pedagogia crítica da aprendizagem. Porto Alegre: Artmed, 1997. 
HAWKINS, M.; NORTON, B. Critical Language Teacher Education. In: BURNS, A.; RICHARDS, J. (eds.). Cambridge Guide to second language teacher education. Cambridge: CUP, p. 30-39, 2009.

JORDÃO, C. M. A posição de professor de inglês: hibridismo, identidade e agência. Revista Let. \& Let. Uberlândia-MG, v.26, n.2, p. 427-442, 2010.

McGOVERN, M. The Media's Influence on Public Perception of Homosexuality. Journal of Research across disciplines. Jacksonville University, p 1-14, 2015. Disponível em: http://www.ju.edu/jrad/documents/michele_submission.pdf Acesso em: 18/01/2016.

MELLO, L.; BRITO, W.; MAROJA, D. Políticas Públicas para a população LGBT no Brasil: notas sobre alcances e possibilidades. Cadenos Pagú, v. 39, p. 403-429, 2012.

MERTON, R. K.; LAZARSFELD, P. F. Comunicação de massa, Gosto Popular e A organização da ação social. In: LIMA, L; C. (org.). Teoria da Cultura de Massa. São Paulo: Paz e Terra, p. 109-134, 2000.

MIZAN, S. Letramento visual na mídia. In: TAKAKI, N. H.; MACIEL, R. F. (orgs.). Letramentos em terra de Paulo Freire. Campinas, São Paulo: Pontes Editores, p. 271282.

MONTE-MÓR, W. Reading Dogville in Brazil: image, language and critical literacy. In: MENEZES DE SOUZA (ed.). Language and Intercultural Communication, Special edition: Language, Culture, Multimodality and Dialogic Emergence. London: Multilingual Matters, p. 124-135, 2006.

MONTE-MÓR, W. Critical literacies, meaning making and new epistemological perspectives. In: Revista Eletronica Matices de Lenguas Estranjeras. N. 2. Bogota: Matices, p. 1-18, 2008.

MONTE MÓR, W. Sobre rupturas e expansão na visão de mundo: seguindo as pegadas e os rastros da formação crítica. In: PESSOA, R. R.; SILVESTRE, V.; MONTE MÓR, W. (Orgs.). Perspectivas críticas de educação linguística no Brasil: trajetórias e práticas de professoras/es universitárias/os de inglês. São Paulo: Pá da Palavra, p. 263276.

PENNYCOOK, A. Critical and Alternative Directions in Applied Linguistics. Australian Review of Applied Linguistics. Monash University Press, v. 33, n. 2, p. 16.116.16, 2010.

RICOUER, P. Interpretation Theory: Discourse and the Surplus of Meaning. Fort Worth: Texan Christian University Press, 1976.

RICOUER, P. Conflitos das Interpretações: Ensaios de Hermenêutica. RJ, Editora Imago, 1978.

ROGOFF, I. Studying Visual Culture. In: MIRZOEFF, N. The Visual Culture Reader. London: Routledge, 2002.

SAID, E. Cultura e Política. São Paulo: Boitempo Editorial, 2007. 
REVISTA X, Curitiba, volume 14, n.4,p. 200-221, 2019

SCORSOLINI-COMIN, F.; SANTOS, M. A. Insensatos afetos: homossexualidade e homofobiana telenovela brasileira. Barbarói, Santa Cruz do Sul, n.36, p.50-66, 2012.

SEVERO, J. Itaú, Ponto Frio e outras 5 empresas declaram apoio ao casamento gay. Disponível em: http://juliosevero.blogspot.com.br/2013/04/itau-ponto-frio-e-outras-5empresas.html. Acesso em: 30 abril 2016.

VILLALBA, P. Beijo gay faz de 'Amor à vida' um marco da TV. Veja, 1 fevereive 2014, p.1. Disponível em http://veja.abril.com.br/blog/quanto-drama/folhetinescas/cercado-detorcida-beijo-gay-faz-de-amor-a-vida-um-marco-da-tv/ Acesso em: 20 junho 2015.

WINDLE, J. A. The role of internationalisation in the schooling of Brazilian elites: distinctions between two class fractions. British Journal of Sociology of Education. London: Routledge, p. 174-192, 2014. 